\section{Estudo da Função Tiroideana em Uma População com Mais de 50 Anos}

\section{RESUMO}

Com objetivo de analisar a freqüência de disfunção tiroideana e de identificar possiveis alterações hormonais decorrentes do envelhecimento, estudamos 198 indivíduos com idade variando de 50 a 85 anos e 106 filhos com idade entre 11 e 49 anos. A prevalência de disfunção tiroideana foi semelhante em ambos grupos (12,6\% no grupo de estudo e $14,1 \%$ entre os filhos). A presença de um ou dois anticorpos antitiroideanos positivos foi também semelhante entre os grupos (9,1\% e $12,3 \%$ para os idosos e filhos respectivamente), embora sem correlação disfunção tiroideana. nos idosos. Os níveis séricos de T3 e FT4 foram significantemente menores entre os indivíduos mais velhos quando comparados com os filhos $(1,27 \pm 0,27 \times 1,39 \pm 0,31 \mathrm{ng} / \mathrm{ml}$ e $0,97 \pm 0,29 \times$ $1,18 \pm 0,76 \mathrm{ng} / \mathrm{dl}$, respectivamente). Não houve diferença entre os grupos quanto aos níveis de TSH, T4 total e TBG. Concluímos que a prevalência de disfunção tiroideana não foi diferente entre os grupos e que a presença de anticorpos antitiroideanos esteve associada com disfunção da tiróide apenas nos indivíduos mais jovens. A correlação inversa dos niveis de T3 e FT4 com a idade pode refletir uma adaptação à menor necessidade dos hormônios com o envelhecimento. (Arq Bras Endocrinol Metab 2002;46/5:557-565)

Descritores: Disfunção tiroideana; Prevalência; Idoso; Hormônios tiroideanos; Anticorpos antitiroideanos

\begin{abstract}
Thyroid Function Studies in a Population Sample Over 50 Years of Age. We evaluated 198 subjects between 50 and 85 years of age (older group) and 106 individuals of their offspring in the age group 11-49 years (younger group) in order to determine the frequency of thyroid dysfunction and also identify possible hormonal changes due to aging. The prevalence of thyroid dysfunction was similar in both groups (12.6\% in the older and $14.1 \%$ in the younger groups). The positivity to one or two antithyroid antibodies was also similar between the groups (9.1\% and $12.3 \%$ for the elderly and the young, respectively), although no correlation with the thyroid dysfunction was found in the elderly. Serum T3 and FT4 levels were significantly lower in the older as compared with the younger subjects $(1.27 \pm 0.27$ vs $1.39 \pm 0,31 \mathrm{ng} / \mathrm{mL}$ and $0.97 \pm 0.29$ vs $1.18 \pm 0.76 \mathrm{ng} / \mathrm{dL}$, respectively). No statistical significant difference was found between the groups regarding TSH, total T4 and TBG levels. We conclude that the prevalence of thyroid dysfunction was similar between the groups and that the positivity to anti-thyroid antibodies was associated with thyroid dysfunction only in the younger subjects. The inverse correlation between T3 and FT4 levels and the age can reflect an adaptation to the lowest requirements for the hormones with the aging. (Arq Bras Endocrinol Metab 2002;46/5:557-565)
\end{abstract}

Keywords: Thyroid dysfunction; Prevalence; Aging; Thyroid antibodies; Thyroid hormones

\section{artigo original}

\author{
Suzan C.L. Mendonça \\ Paulo T. Jorge
}

Recebido em 20/02/02 Revisado em 06/05/02 Aceito em 10/06/02 


\begin{abstract}
$\mathrm{A}^{\mathrm{p}}$ PREVALÊNCIA DE DISFUnÇÕES DA tiróide depende de fatores étnicos, do nível de ingestão de iodo e ainda do modelo de estudo utilizado em uma determinada população. Parece haver um consenso de que o hipotiroidismo seja mais freqüente no idoso, embora estudos de prevalência nesta faixa etária mostrem índices que variam de $0,4 \%$ a $3,8 \%$ nos homens e $0,7 \%$ a 11,6\% nas mulheres (1-11). Para o hipertiroidismo, os estudos populacionais em diferentes regiões mostram valores que variam de $0,2 \%$ a $3 \%$ na população idosa $(3-7,12)$. Um estudo intra-hospitalar encontrou incidência sete vezes maior de hipertiroidismo após 60 anos de idade (13).

Também não há consenso na literatura sobre os níveis dos hormônios tiroideanos e tireotrofina (TSH) nos idosos. Alguns autores concordam que, com a idade, ocorra uma diminuição dos níveis séricos de T3, T4 e FT4 $(9,14,18-23,25,26)$, enquanto para outros estes se mantém inalterados $(14,23,24,27)$ com o envelhecimento. Níveis elevados $(4,8,14)$ de TSH, baixos (15-17) ou inalterados (18) já foram descritos na população idosa. A avaliação dos hormônios tiroideanos em idosos é complexa, devido à presença de doenças concomitantes e uso freqüente de medicações que podem influenciar a dosagem dos hormônios tiroideanos.

Tendo em vista estas particularidades na interpretação dos testes de função tiroideana na população idosa e a dependência dos fatores locais na prevalência de disfunções da tiróide, o objetivo deste trabalho foi estudar a freqüência de hipotiroidismo e hipertiroidismo em uma população com mais de 50 anos, comparada com um grupo controle composto pelos filhos. Avaliamos ainda os níveis séricos de TSH, TBG, anticorpos antitiroideanos e hormônios tiroideanos nesta população, estratificada por faixa etária.
\end{abstract}

\section{CASUÍSTICA E MÉTODOS}

O estudo foi realizado em Uberlândia, $\mathrm{MG}$, no Centro de Educação e Assistência Integrada (CEAI), órgão municipal que visa integração social dos idosos através de lazer, cultura e atividade física. Os idosos cadastrados para prática desportiva no período de fevereiro de 1996 a março de 1997 foram convidados a participar do estudo e esclarecidos sobre a finalidade do trabalho. Foram incluídos 198 indivíduos (38 homens e 160 mulheres), correspondendo a $82,5 \%$ da população cadastrada, com idade variando de 50 a 85 anos (mediana de 63 anos). O grupo controle foi composto por 106 filhos (31 homens e 75 mulheres) com idade variando de 11 a 49 anos (mediana de 33), que aceitaram participar do estudo (não randomizado), desde que não tivessem conhecimento prévio dos resultados dos exames dos pais. Todos indivíduos do grupo de estudo e os controles foram avaliados quanto à prevalência de disfunção tiroideana, mesmo aqueles que tinham diagnóstico prévio. Para análise dos níveis de TSH, TBG e dos hormônios tiroideanos por faixas etárias, foram excluídos, nos dois grupos, os portadores de disfunção tiroideana ou que estivessem usando drogas que pudessem alterar as suas dosagens e aqueles que tinham bócio ou anticorpos antitiroideanos positivos. Uma vez que tivemos a intenção de avaliar se, com o envelhecimento, haveria uma nova faixa de normalidade para os hormônios, retiramos doenças da tiróide que pudessem alterar estas dosagens, já que o único fator que quisemos analisar foi a idade.

Os dois grupos responderam um questionário sobre doenças pré-existentes e uso de medicamentos que pudessem interferir na dosagem dos hormônios tiroideanos ou do TSH. Foi realizado, ainda, exame clínico e laboratorial (dosagem de sódio, potássio, uréia creatinina, albumina, hemograma, glicemia e lipidograma) e a dosagem dos hormônios tiroideanos T3, T4, FT4, TSH, TBG, anticorpo antitireoglobulina e antimicrossomal. Para dosagem dos hormônios usamos quimioluminescência com Kit Immulit da Diagnostic Products Corporation. Foram considerados normais valores de T4 de 4,5 a $13 \mu \mathrm{g} / \mathrm{dl}$, T3 de 0,5 a $2, \mathrm{lng} / \mathrm{ml}, \mathrm{FT} 4$ de 0,8 a $1,9 \mathrm{ng} / \mathrm{dl}$, TSH de 0,3 a $4,2 \mu \mathrm{U} / \mathrm{ml}$ e $\mathrm{TBG}$ de 13 a $33 \mu \mathrm{g} / \mathrm{ml}$. Os anticorpos antitiroideanos foram dosados através de aglutinação de partículas de gel e foram considerados positivos títulos maiores do que 1:100.

As disfunções tiroideanas foram classificadas da seguinte forma:

Hipotiroidismo: níveis elevados de TSH e baixos de FT4;

Hipotiroidismo subclínico: níveis de TSH maiores que $5 \mu \mathrm{U} / \mathrm{ml}$ e normais de T3 e FT4;

Hipertiroidismo: níveis baixos de TSH e elevados de T3 ou FT4;

Hipertiroidismo subclínico: níveis de TSH menores que $0,2 \mu \mathrm{U} / \mathrm{ml}$ e normais de T3 e FT4.

Este estudo foi analisado e aprovado pela Comissão de Ética Médica do Hospital de Clínicas da Universidade Federal de Uberlândia.

Para a análise estatística utilizamos o teste $\mathrm{Z}$ na comparação das prevalências entre os dois grupos. A comparação das médias dos níveis de hormônios

Arq Bras Endocrinol Metab vol $46 n^{\circ} 5$ Outubro 2002 
tiroideanos entre os grupos foi feita pelo teste "T de student". Para avaliação estatística dos coeficientes de correlação entre idade e concentração sérica dos hormônios tiroideanos, foi calculada a regressão linear e análise de variância, aplicando-se o Software EPI INFO-6, 1997 da Organização Mundial de Saúde e do Centers for Disease Control and Prevention. Foram considerados significantes valores de $\mathrm{p}<0,05$.

\section{RESULTADOS}

\section{Prevalência de disfunção tiroideana}

No grupo de 198 indivíduos com mais de 50 anos foram detectados 25 casos de disfunção tiroideana $(12,6 \%)$, sendo 21 mulheres e 4 homens. Desses, 2 (1\%) eram portadores de hipotiroidismo, um $(0,5 \%)$ de hipertiroidismo; 14 indivíduos $(7,1 \%)$ apresentavam hipotiroidismo subclínico e 8 (4\%) hipertiroidismo subclínico (tabela 1 ). Nenhum deles fazia uso de medicamentos que pudessem ter alterado os resultados. Dois portadores de hipertiroidismo subclínico tinham sido submetidos à tiroidectomia por bócio há pelo menos 12 anos, mas não faziam acompanhamento médico, e um caso de hipotiroidismo subclínico tinha diagnóstico prévio de hipotiroidismo pós cirúrgico e fazia uso de levotiroxina sódica para reposição. Os demais desconheciam ser portadores de doença tiroideana. Neste grupo tivemos um caso de hipo-TBGnemia confirmada laboratorialmente por valores muito baixos de T3, T4 e TBG, mas normais de TSH e FT4.

No grupo controle, de 106 indivíduos, tivemos 15 casos $(14,1 \%)$ de disfunção tiroideana (2 homens e 13 mulheres), sendo o hipotiroidismo responsável por 3 casos $(2,8 \%)$ e o hipotiroidismo subclínico por 10 $(9,4 \%)$. Houve apenas dois casos $(1,9 \%)$ de hipertiroidismo, um deles na forma subclínica (tabela 2). Em dois portadores de hipotiroidismo subclínico, um deles tinha história de tiroidectomia por bócio e o outro passado de uso de Propilthiouracil ${ }^{Æ}$. Um dos casos de hipotiroidismo franco $(\mathrm{TSH}>75 \mathrm{mUI} / \mathrm{ml}$ ) tinha diagnóstico anterior, mas fazia uso irregular do hormônio tiroideano. Os demais não sabiam ser portadores de doença tiroideana. Os pacientes não faziam uso de medicamentos que pudessem ter alterado os resultados. Em uma mesma família, três irmãos tiveram seus exames alterados, fato que contribuiu para que a prevalência de disfunção tiroideana fosse maior neste grupo. Nesta família citada, a mãe não tinha disfunção tiroideana ou anticorpos positivos.

A diferença na prevalência de disfunção tiroideana não foi estatisticamente significante entre os dois grupos $(\mathrm{p}=0,24)$. (gráfico 1 , tabela 3$)$.

Tabela 1. Características dos pacientes com disfunção tiroideana no grupo com idade superior a 50 anos.

\begin{tabular}{|c|c|c|c|c|c|c|c|c|}
\hline $\begin{array}{l}\text { ldade } \\
\text { (anos) }\end{array}$ & Sexo & Diagnóstico & $\begin{array}{c}\text { T3 } \\
(\mathrm{ng} / \mathrm{ml})\end{array}$ & $\begin{array}{c}\mathrm{T4} \\
(\mu \mathrm{g} / \mathrm{dl})\end{array}$ & $\begin{array}{c}\mathrm{FT} 4 \\
(\mathrm{ng} / \mathrm{dl})\end{array}$ & $\begin{array}{c}\text { TSH } \\
(\mu \mathrm{U} / \mathrm{ml})\end{array}$ & $\begin{array}{c}\text { Anticorpo } \\
\text { anti tireoglobulina }\end{array}$ & $\begin{array}{c}\text { Anticorpo } \\
\text { anti microssomal }\end{array}$ \\
\hline 53 & $\mathrm{~F}$ & Hiper. Subcl. & 1,2 & 9,1 & 1,4 & 0,03 & Negativo & Negativo \\
\hline 59 & $\mathrm{~F}$ & Hiper. Subcl. & 1,4 & 8,5 & 1,6 & 0,09 & Negativo & Negativo \\
\hline $60^{* *}$ & $\mathrm{~F}$ & Hiper. Subcl. & 1,7 & 9 & 1,3 & 0,04 & Negativo & Negativo \\
\hline 61 & $\mathrm{~F}$ & Hiper. Subcl. & 1,5 & 11,4 & 0,8 & 0,2 & Negativo & Negativo \\
\hline 63 & $\mathrm{~F}$ & Hiper. Subcl. & 1,5 & 12,7 & 1,1 & 0,2 & Negativo & Negativo \\
\hline 65 & $\mathrm{~F}$ & Hiper. Subcl. & 1,9 & 10,1 & 1,2 & 0,2 & Negativo & Negativo \\
\hline $66^{* *}$ & $\mathrm{~F}$ & Hiper. Subcl. & 1,8 & 10,9 & 1,1 & 0,02 & Negativo & Negativo \\
\hline 69 & $\mathrm{~F}$ & Hiper. Subcl. & 1,9 & 10,8 & 1,1 & 0,2 & Negativo & Negativo \\
\hline 53 & $\mathrm{~F}$ & Hipertir. & 2,1 & 18,2 & 3,3 & 0,009 & Negativo & Negativo \\
\hline 52 & $\mathrm{~F}$ & Hipo. Subcl. & 1,3 & 7,0 & 1,5 & 6,9 & Negativo & Negativo \\
\hline 54 & $\mathrm{~F}$ & Hipo. Subcl. & 1,8 & 9,3 & 1,7 & 6,8 & Negativo & Negativo \\
\hline 59 & $\mathrm{~F}$ & Hipo. Subcl. & 1,2 & 6,6 & 0,8 & 16,8 & Negativo & $1 / 6400$ \\
\hline 59 & $M$ & Hipo. Subcl. & 1,5 & 8,0 & 0,9 & 6,3 & Negativo & Negativo \\
\hline 60 & $\mathrm{~F}$ & Hipo. Subcl. & 1,1 & 9,3 & 0,9 & 12,8 & Negativo & $1 / 1600$ \\
\hline $62^{* *}$ & $\mathrm{~F}$ & Hipo. Subcl. & 1,3 & 10,0 & 1,5 & 5,2 & Negativo & Negativo \\
\hline 64 & $\mathrm{~F}$ & Hipo. Subcl. & 1,8 & 9,6 & 1,1 & 11,7 & Negativo & Negativo \\
\hline 64 & $\mathrm{~F}$ & Hipo. Subcl. & 1,1 & 13,2 & 0,8 & 5,7 & Negativo & Negativo \\
\hline 67 & $M$ & Hipo. Subcl. & 1,6 & 8,2 & 0,9 & 11,7 & Negativo & Negativo \\
\hline 68 & $\mathrm{~F}$ & Hipo. Subcl. & 1,7 & 11,2 & 0,7 & 6,9 & Negativo & Negativo \\
\hline 69 & $\mathrm{~F}$ & Hipo. Subcl. & 1,4 & 8,6 & 1,0 & 8,8 & Negativo & Negativo \\
\hline 70 & $M$ & Hipo. Subcl. & 1,1 & 10,8 & 0,9 & 7,1 & Negativo & Negativo \\
\hline 70 & $\mathrm{~F}$ & Hipo. Subcl. & 1,1 & 11,0 & 1,0 & 5,0 & * & * \\
\hline 75 & $\mathrm{~F}$ & Hipo. Subcl. & 1,4 & 8,1 & 1,0 & 5,6 & Negativo & $1 / 1600$ \\
\hline 72 & $\mathrm{~F}$ & Hipotir. & 0,7 & 2,5 & 0,001 & 210,0 & Negativo & Negativo \\
\hline 85 & $M$ & Hipotir. & 0.7 & 4,8 & 0,4 & 14,4 & Negativo & $1 / 25600$ \\
\hline
\end{tabular}

* Dosagem não realizada

** Diagnóstico prévio 
Função Tiroideana em Idosos

Mendonça \& Jorge

Tabela 2. Características dos pacientes com disfunção tiroideana no grupo controle composto por filhos com idade até 50 anos

\begin{tabular}{|c|c|c|c|c|c|c|c|c|}
\hline $\begin{array}{l}\text { Idade } \\
\text { (anos) }\end{array}$ & Sexo & Diagnóstico & $\begin{array}{c}\mathrm{T} 3 \\
(\mathrm{ng} / \mathrm{ml})\end{array}$ & $\begin{array}{c}\mathrm{T} 4 \\
(\mu \mathrm{g} / \mathrm{dl})\end{array}$ & $\begin{array}{c}\mathrm{FT} 4 \\
(\mathrm{ng} / \mathrm{dl})\end{array}$ & $\begin{array}{c}\text { TSH } \\
(\mu \mathrm{U} / \mathrm{ml})\end{array}$ & $\begin{array}{c}\text { Anticorpo } \\
\text { anti tireoglobulina }\end{array}$ & $\begin{array}{c}\text { Anticorpo } \\
\text { anti microssomal }\end{array}$ \\
\hline 33 & $\mathrm{~F}$ & Hiper. Subcl. & 1,2 & 11,0 & 1,9 & 0,07 & Negativo & Negativo \\
\hline 30 & $\mathrm{~F}$ & Hipertir. & 1,5 & 15,6 & 2,3 & 0,04 & Negativo & Negativo \\
\hline 25 & $\mathrm{~F}$ & Hipo. Subcl. & 1,8 & 9,1 & 1,2 & 9,3 & $1 / 409600$ & $1 / 100$ \\
\hline 28 & $\mathrm{~F}$ & Hipo. Subcl. & 1,8 & 11,1 & 1,3 & 6,5 & Negativo & Negativo \\
\hline 37 & M & Hipo. Subcl. & 1,2 & 8,6 & 1,5 & 8,1 & $1 / 409600$ & $1 / 100$ \\
\hline 43 & $\mathrm{~F}$ & Hipo. Subcl. & * & 6,7 & 0,8 & 8,2 & Negativo & $1 / 25600$ \\
\hline 43 & $\mathrm{~F}$ & Hipo. Subcl. & 1,0 & 7,5 & 1,1 & 6,2 & Negativo & $1 / 400$ \\
\hline $43^{* *}$ & $\mathrm{~F}$ & Hipo. Subcl. & 1,5 & 7,5 & 0,8 & 5,0 & Negativo & Negativo \\
\hline $45^{\star \star}$ & $M$ & Hipo. Subcl. & 1,6 & 6,9 & 0,8 & 6,3 & Negativo & $1 / 1600$ \\
\hline 45 & $\mathrm{~F}$ & Hipo. Subcl. & 1,1 & 8,4 & 1,3 & 7,3 & Negativo & Negativo \\
\hline 48 & $\mathrm{~F}$ & Hipo. Subcl. & 2,0 & 9,2 & 1,0 & 6,7 & Negativo & Negativo \\
\hline 50 & $\mathrm{~F}$ & Hipo. Subcl. & 0,9 & 7,0 & 0,8 & 5,3 & Negativo & $1 / 6400$ \\
\hline 25 & $\mathrm{~F}$ & Hipotir. & 0,8 & 4,0 & 0,6 & 75,0 & Negativo & $1 / 6400$ \\
\hline 26 & $\mathrm{~F}$ & Hipotir. & 0,8 & 0,4 & 0,1 & 75,0 & Negativo & $1 / 400$ \\
\hline $42^{\star *}$ & $\mathrm{~F}$ & Hipotir. & 0,9 & 3,7 & 0,3 & 75,0 & $1 / 100$ & $1 / 400$ \\
\hline
\end{tabular}

* Dosagem não realizada

** Diagnóstico prévio

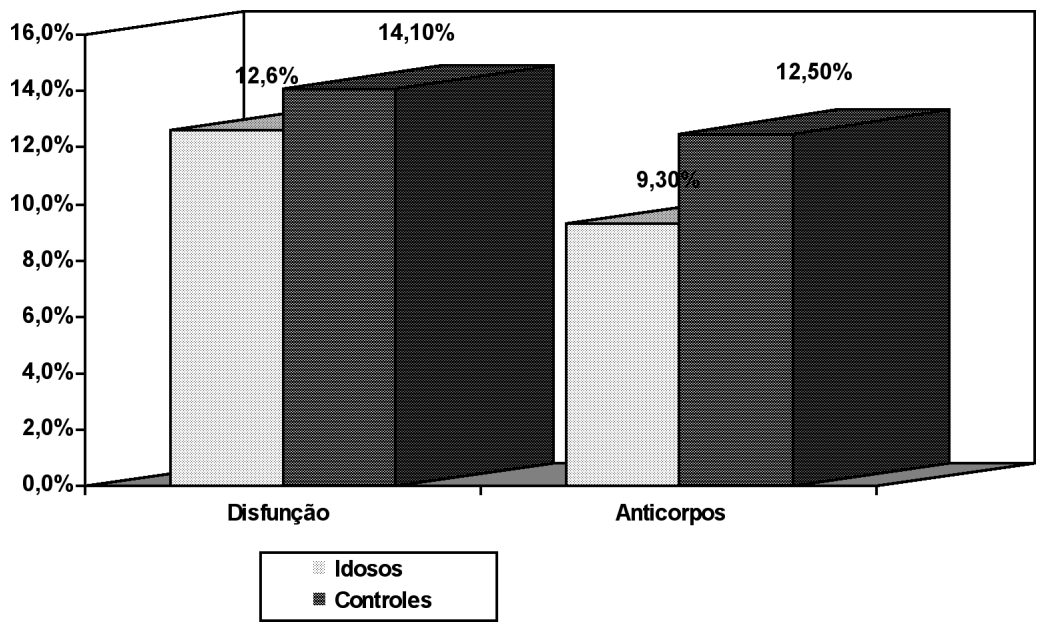

Gráfico 1. Prevalência de disfunção e anticorpos antitiroideanos nos indivíduos com mais de 50 anos e no grupo controle composto pelos filhos de meia-idade.

Tabela 3. Prevalência de disfunção tiroideana e anticorpos antitiroideanos nos indivíduos com mais de 50 anos e seus filhos, estratificados por faixa etária.

\begin{tabular}{cccccc}
\hline $\begin{array}{l}\text { Idade } \\
\text { (anos) }\end{array}$ & Número & $\begin{array}{c}\text { Hipotiroidismo (\%) } \\
\text { subclínico }\end{array}$ & $\begin{array}{c}\text { Hipertiroidismo (\%) } \\
\text { clínico }\end{array}$ & $\begin{array}{c}\text { Anticorpos } \\
\text { subclínico }\end{array}$ & 0 \\
Antitiroideanos (\%)
\end{tabular}




\section{Prevalência de anticorpos antitiroideanos}

No grupo de estudo, a prevalência de pelo menos um dos anticorpos antitiroideanos positivos foi de $9,1 \%$ (18 casos), sendo que $14(77,7 \%)$ não apresentavam disfunção tiroideana. Os poucos casos com disfunção tratavam-se de hipotiroidismo (subclínico e clínico).

A prevalência de pelo menos um dos anticorpos antitiroideanos positivos no grupo controle foi de $12,3 \%$ ( 13 casos) e 8 deles $(61,5 \%)$ eram portadores de hipotiroidismo (subclínico ou clínico). (gráfico 1 , tabela 3). Se excluídos novamente os três irmãos que tiveram anticorpos positivos, a nova prevalência seria de $9,4 \%$.

Apesar da tendência do grupo controle apresentar uma maior prevalência de anticorpos positivos, essa diferença não se mostrou significante $(\mathrm{p}=0,39)$. Um achado interessante, foi a grande associação entre anticorpos positivos e disfunção tiroideana observada no grupo controle, mas não no grupo de estudo (gráfico 2).

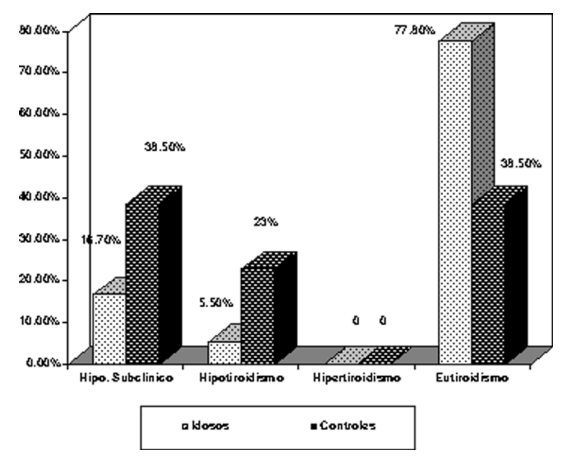

Gráfico 2. Função tiroideana nos portadores de anticorpos antitiroideanos positivos.

\section{Nívei dos hormônios tiroideanos, TSH e TBG}

As médias dos níveis séricos de T3, T4, FT4, TSH e TBG foram calculadas para os 263 indivíduos sem doença tiroideana, bócio ou anticorpos antitiroideanos e encontram-se na tabela 4.

A comparação dos níveis de T3 e FT4 mostrou valores significantemente menores nos indivíduos com mais de 50 anos $(\mathrm{p}<0,01)$. Não houve diferença dos níveis de T4, TSH e TBG entre os grupos.

Toda amostra composta pelo grupo de estudo e pelo grupo controle foi estratificada, e a média dos níveis séricos dos hormônios tiroideanos, TSH e TBG foi calculada para cada faixa etária. Os resultados estão relacionados na tabela 5 . A única medicação usada que poderia ter alterado os resultados foi o estrógeno para reposição hormonal em algumas mulheres. Quando estas foram excluídas, não houve alteração da média dos níveis de T4 e TBG, e então foram mantidas na análise.

Houve uma correlação inversa dos níveis de T3 com a idade $(r=-0,26 ; y=1,58-0,005 x ; p<0,01)$. O

Tabela 4. Comparação das médias dos hormônios tiroideanos, TSH e TBG nos indivíduos eutiroideanos com idade superior a 50 anos e seus filhos.

\begin{tabular}{ccc}
\hline $\begin{array}{c}\text { Variáveis } \\
\text { estudadas }\end{array}$ & $\begin{array}{c}\text { Grupo de Estudo } \\
(n=172)\end{array}$ & $\begin{array}{c}\text { Grupo Controle } \\
(n=91)\end{array}$ \\
\hline $\mathrm{T}^{*}(\mathrm{ng} / \mathrm{ml})$ & $1,27 \pm 0,27$ & $1,39 \pm 0,31$ \\
$\mathrm{~T} 4(\mu \mathrm{g} / \mathrm{dl})$ & $9,19 \pm 2,02$ & $8,84 \pm 2,02$ \\
$\mathrm{FT}^{*}(\mathrm{ng} / \mathrm{dl})$ & $0,97 \pm 0,29$ & $1,18 \pm 0,76$ \\
$\mathrm{TSH}(\mu \mathrm{U} / \mathrm{ml})$ & $1,66 \pm 1,03$ & $1,77 \pm 1,0$ \\
$\mathrm{TBG}(\mu \mathrm{g} / \mathrm{ml})$ & $25,36 \pm 8,24$ & $24,59 \pm 7,11$ \\
\hline
\end{tabular}

* Diferença estatisticamente significante $(p<0,01)$.

Tabela 5. Níveis médios dos Hormônios Tiroideanos, TBG e TSH no grupo composto por pessoas com mais de 50 anos e seus filhos, sem doença tiroideana, estratificados por faixa etária.

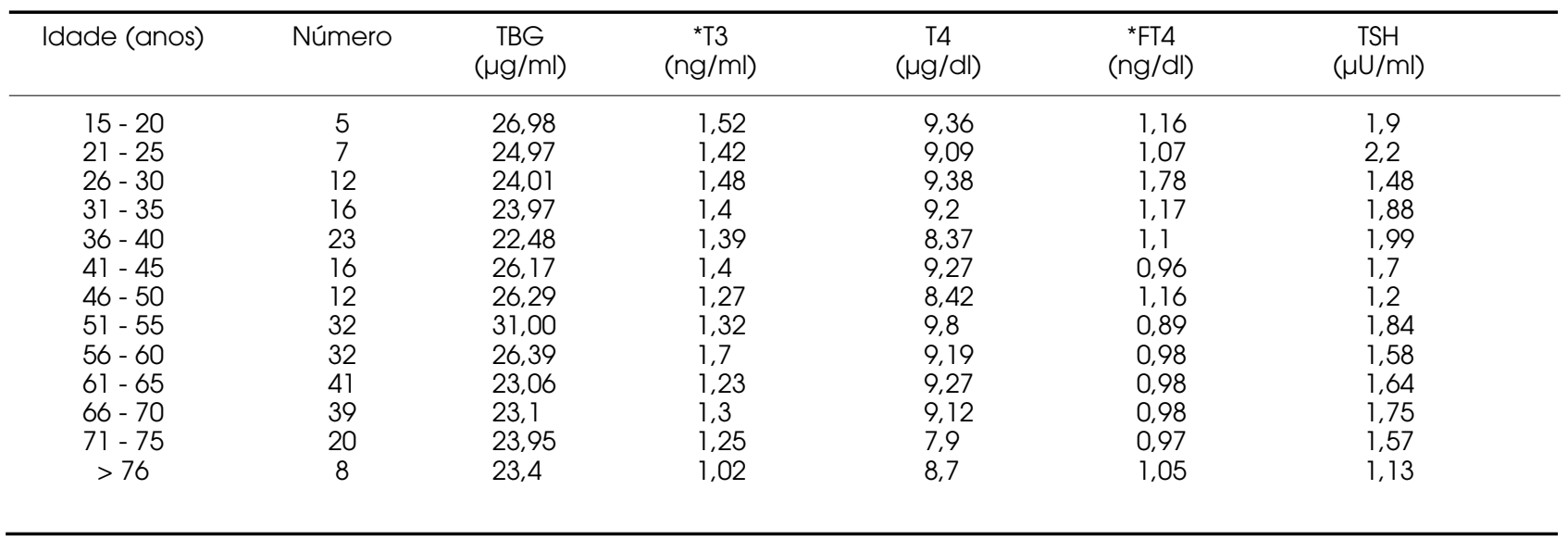

* Diferença estatisticamente significante $(p<0,01)$ 
mesmo foi observado com o FT4 ( $r=-0,19 ; \mathrm{y}=1,22-$ $0,0037 \mathrm{x} ; \mathrm{p}<0,01$ ). Por outro lado, os níveis de TBG, T4 e TSH não mostraram diferença estatisticamente significante nas diversas faixas etárias.

\section{DISCUSSÃO}

Nós observamos alta prevalência de disfunção tiroideana tanto na população com mais de 50 anos $(12,6 \%)$ como no grupo controle $(14,1 \%)$, sendo que, em ambos, o hipotiroidismo subclínico foi a alteração mais freqüente. A maioria dos casos de disfunção tiroideana não tinha diagnóstico prévio, fato observado nos dois grupos. Dois estudos nacionais revelam dados parecidos, com $7 \%$ de prevalência de hipotiroidismo no Rio de Janeiro (28) e $21,5 \%$ de hipotiroidismo subclínico na Bahia (29). Diversos outros estudos (tabela 6) apontam resultados variados, mas a maioria deles não dispõe de grupo controle. Os levantamentos de Okamura e cols. (7), Tunbridge e cols. (4) e Canaris e cols. (30) mostraram uma maior prevalência de disfunção tiroideana nos idosos quando comparados com os controles. Já no estudo de Sawin e cols. (14), embora tivesse grupo controle, esses dados não foram comparados. Em nosso trabalho, a prevalência semelhante de disfunção tiroideana entre indivíduos com mais de 50 anos e o grupo controle pode demonstrar uma alta prevalência de doença tiroideana nesta população, talvez em função de fatores ambientais e alimentares, sem correlação com o envelhecimento, como tem sido proposto. A crítica feita ao nosso grupo controle seria a técnica usada para seleção, pois a mesma não foi randomizada. Poderíamos considerar que os filhos que aceitaram participar do estudo seriam aqueles cujos pais tiveram exames alterados. Esse aspecto foi minimizado, uma vez que os filhos, ao aceitarem participar do projeto, desconheciam os resultados dos exames dos pais e, além disso, foram convidados a participar de um estudo cujo objetivo visava o diagnóstico de outras patologias altamente prevalentes, como Diabetes Mellitus, Dislipidemia e Hipertensão Arterial.

Outro fato que pode explicar a grande variedade de resultados nos vários estudos sobre prevalência de disfunção tiroideana seria a dificuldade em caracterizar disfunção. Níveis pouco elevados de TSH (entre 5 e $10 \mathrm{mU} / \mathrm{ml}$ ) podem representar pequenas variações do ensaio, que, se repetidos, evidenciam uma tendência de "regressão à média" (31). No entanto, neste estudo, bem como na maioria de outros estudos de prevalência $(2,4,5,7,11,12,14,20,30,32)$, níveis pouco elevados de TSH e normais dos hormônios tiroideanos foram considerados hipotiroidismo subclínico. Em dois estudos $(6,10)$, casos de TSH pouco elevados foram reavaliados, com objetivo de evitar que valores falsamente elevados de TSH, por causa da reação cruzada com imunoglobulinas, fossem considerados alterados. Os baixos índices de prevalência encontrados por Lloyd \& Golberg (1), podem ser explicados pelo fato de ter sido utilizado o diagnóstico clínico, e apenas os casos suspeitos foram avaliados laboratorialmente. Parle e cols. (8) acompanharam idosos com valores pouco elevados de TSH e FT4 nor-

Tabela 6. Estudos transversais sobre prevalência de disfunção tiroideana em idosos.

\begin{tabular}{|c|c|c|c|c|c|c|c|}
\hline \multirow[t]{2}{*}{ Autores } & \multirow[t]{2}{*}{ Ano } & \multirow[t]{2}{*}{ Local } & \multirow[t]{2}{*}{$\mathbf{N}$} & \multirow[t]{2}{*}{ Idade } & \multicolumn{2}{|c|}{$\begin{array}{c}\text { Hipotiroidismo } \\
(\%)\end{array}$} & \multirow[t]{2}{*}{$\begin{array}{l}\text { Hipertiroidismo } \\
(\%)\end{array}$} \\
\hline & & & & & Subclínico & Clínico & \\
\hline Lloyd \& Goldberg & 1961 & Jamaica & 58 & 70 (média) & * & 1,7 & 0,5 \\
\hline Bahemuka \& Hodkinson & 1975 & Inglaterra & 2000 & 80 (média) & * & * & 2,3 \\
\hline Palmer & 1977 & Nova Zelândia & 187 & $>60$ & * & 2,6 & 3 \\
\hline Tunbridge e cols. \# & 1977 & Reino Unido & 2779 & $>18$ & 2,8 & $<0,1$ & $<0,1$ \\
\hline Sawin e cols. \# & 1979 & EUA & 344 & $>60$ & 14,4 & 5,9 & * \\
\hline Campbell e cols. & 1981 & Nova Zelândia & 559 & $>65$ & 1,64 & 0,94 & 0,47 \\
\hline Falkenberg e cols. & 1983 & Suécia & 1442 & $>60$ & 0,9 & 0,6 & 1,9 \\
\hline Heikoff e cols. & 1984 & EUA & 189 & $>60$ & 4,7 & 1,6 & * \\
\hline Sawin e cols. & 1985 & EUA & 2139 & $>60$ & 2,7 & 1,7 & * \\
\hline Linvingston e cols. & 1987 & EUA & 125 & $>60$ & 4,3 & 7,6 & 0,8 \\
\hline Okamura e cols. \# & 1989 & Japão & 2421 & $>40$ & 8,7 & 1,1 & $<0,3$ \\
\hline Bagehi e cols. & 1990 & EUA & 968 & $>55$ & * & 7,3 & 2,5 \\
\hline Sundbeck e cols. & 1991 & Suécia & 786 & 85 & * & 3,9 & 0,6 \\
\hline Bemben e cols. & 1994 & EUA & 283 & $>60$ & 14,8 & 1,0 & * \\
\hline Canaris e cols. \# & 1995 & EUA & 25862 & $>18$ & 9,0 & 0,4 & 2,2 \\
\hline Alderete e cols. & 1996 & Brasil & 100 & $>65$ & * & 7,0 & * \\
\hline Esse estudo \# & 1998 & Brasil & 198 & $>50$ & 7,0 & 1,0 & 0,5 \\
\hline
\end{tabular}

* Dados não apresentados.

\# Trabalhos com Grupo Controle. 
mais por 12 meses e observaram que $17,8 \%$ desenvolveram níveis baixos de FT4. Considerando que a evolução de níveis pouco elevados de TSH é controversa, podendo retornar ao normal na maioria dos casos (8), a aplicação de rastreamento de rotina na população idosa pode ser injustificada se analisarmos o custo-benefício do procedimento.

A tabela 6 mostra resultados dos vários estudos transversais para disfunção tiroideana.

Nossos resultados mostraram, ainda, uma prevalência de anticorpos antitiroideanos semelhante nos dois grupos, embora sem correlação com disfunção tiroideana entre os idosos. Sawin e cols. (32) e Roti e cols. (33) confirmaram esses dados, não encontrando disfunção tiroideana na maioria dos idosos com anticorpos positivos. No grupo controle houve importante correlação entre positividade dos anticorpos e doença tiroideana, principalmente o hipotiroidismo subclínico, o que leva à hipótese de que a tiroidite auto-imune seja a principal causa de hipotiroidismo na amostra estudada, com menos de 50 anos. Mariotti e cols. (34), em uma revisão não muito recente, comentam que a prevalência de anticorpos antitiroideanos é menor em idosos com doença tiroideana estabelecida, concluindo que o fenômeno tiroideano auto-imune $\mathrm{e}$ a doença tiroideana auto-imune sejam entidades dissociadas. Dois estudos $(35,36)$ sugerem que a presença isolada de anticorpos antitiroideanos positivos não prediz falência tiroideana na população idosa, mas naqueles com anticorpos positivos e níveis elevados de TSH, o risco de hipotiroidismo é maior. Os estudos de prevalência de anticorpos antitiroideanos em idosos mostram grande diversidade de resultados, dependendo da sensibilidade dos métodos usados para dosagem e provavelmente das características das populações estudadas (4,8,9,12,37-39). Tomimori e cols. (40), avaliando 547 indivíduos com idade entre 27 e 58 anos, encontraram valores muito parecidos com o presente estudo, em uma área urbana de São Paulo. Anticorpos antitiroideanos estavam presentes em 13,4\% da amostra e, dentre os indivíduos com anticorpos positivos, 37,5\% tinham hipotiroidismo subclínico.

Em nossa casuística, a média dos níveis de T3 e FT4 foram significantemente menores no grupo dos idosos, com uma correlação inversa em função da idade, como confirmado pela regressão linear. Os níveis de TSH, T4 e TBG não foram diferentes nos dois grupos. Embora alguns autores tenham demonstrado níveis de T4 e FT4 diminuídos nos idosos $(9,14,19,20-22$,$) , outros (23,24)$ não mostraram variação desses hormônios com a idade. Um estudo com idosos internados demonstrou que os níveis de FT4 diminuem com a idade, mas aumentam proporcionalmente com a gravidade da doença $(41)$. Com relação aos níveis séricos de $\mathrm{T} 3$, vários estudos demonstraram uma diminuição progressiva com a idade $(9,18,19,23,25,26)$, chegando a $5,1 \mathrm{ng} / \mathrm{dl}$ por década (25), embora o T3 reverso não tenha mostrado a mesma tendência $(23,26)$. Por outro lado, outros trabalhos não confirmaram esta tendência na queda do T3 em função da idade $(14,24,27)$.

Pode ser que, embora a nossa amostra não seja hospitalar, alguns casos de doenças crônicas mais comuns nos idosos, como Diabetes Mellitus, tenham contribuído para valores mais baixos de T3 no total da amostra. Kabadi \& Premachandra (42) mostraram que níveis de T3 eram menores e os de RT3 maiores nos idosos portadores de diabetes descompensado. Olsen e cols. (43) avaliaram o efeito das doenças sobre os níveis de T3, confirmando valores baixos nos idosos doentes em relação aos saudáveis, o que foi confirmado por Bermudez e cols. (44). Burrows e cols. (45), investigando testes de função tiroideana em adultos normais e idosos internados e não internados, encontraram níveis baixos de $\mathrm{T} 3$ apenas nos internados $\mathrm{e}$ sem correlação com o estado clínico, o que reforça a hipótese de que a diminuição dos níveis de T3 não seja secundária apenas ao processo de envelhecimento. A possibilidade levantada para explicar os baixos níveis de T3 seria uma diminuição na conversão periférica de T4 em T3, condição esta chamada "T4 eutiroidismo", que seria responsável pela manutenção do "status" eutiroideano no idoso doente.

Os valores mais baixos de FT4 nos idosos não foram acompanhados de alteração na TBG e a explicação para essa diferença não está clara, talvez ocorra uma adaptação a necessidades menores do T4 com a idade (46). Apesar dos níveis médios de T3 e FT4 terem sido significantemente menores entre os idosos, achamos que não se justifica a elaboração de valores diferentes de normalidade para esta população, uma vez que, embora menores, encontravam-se dentro dos limites estabelecidos pelo ensaio.

Para a TBG, o envelhecimento poderia levar a aumento (19), diminuição (47) ou nenhuma alteração (23), como foi descrito em alguns estudos.

Alguns estudos $(4,8,14)$ encontraram níveis elevados de TSH em idosos, o que pode refletir uma prevalência maior de hipotiroidismo nas populações estudadas, e não uma alteração decorrente do processo de envelhecimento. Hershman e cols. (18), em um modelo de estudo parecido com o nosso, não mostraram alteração do TSH nos homens idosos, embora esses níveis tenham sido um pouco menores 
nas mulheres idosas. Por outro lado, para Sawin e cols. (17), níveis baixos de TSH são muito comuns nos idosos, e têm um baixo valor preditivo positivo para ocorrência de hipertiroidismo. Ehrhmann e cols. (48) analisaram ensaios sensíveis de TSH no diagnóstico de disfunção tiroideana e concluíram que esses apresentam muitas limitações como exames de primeira linha, independentemente da faixa etária. Dentre os fatores citados pelos autores como envolvidos em confusão no diagnóstico estão as doenças não tiroideanas, as doenças psiquiátricas agudas e o uso de drogas, responsáveis por níveis baixos de TSH em $17 \%$ da amostra estudada.

Em nossa região, a doença tiroideana não apresenta freqüência maior na população idosa, ao contrário do que revela a maioria dos estudos. Os níveis séricos de T3 e FT4 foram menores na população com mais de 50 anos e houve uma correlação inversa com a idade, o que foi também demonstrado em vários trabalhos. Provavelmente, as características da população tenham o papel mais importante na ocorrência destas alterações, embora apenas estes dados não possam invalidar a importância do envelhecimento nestes achados.

\section{REFERÊNCIAS}

1. Lloyd WH, Goldberg IJL. Incidence of hypothyroidism in the elderly. Br Med J 1961;nov. 11:1256-9.

2. Bahemuka M, Hodkinson HM. Screening for hypothyroidism in elderly inpatients. Br Med J 1975;2:601-3.

3. Palmer KT. A prospective study into thyroid disease in a geriatric unit. N Z Med J 1977;86(597):323-4.

4. Tunbridge WMG, Evered DC, Hall R, Appleton D, Brewis $\mathrm{M}$, Clark $\mathrm{F}$, et al. The spectrum of thyroid disease in a community: The Whickham survey. Clin Endocrinol 1977;7(6):481-93.

5. Campbell AJ, Reinken J, Allan BC. Thyroid disease in the elderly in the community. Age and ageing 1981;10:4752.

6. Falkenberg M, Kagedal B, Noor A. Screening of an elderly female population for hypo and hyperthyroidism by use of a thyroid hormone panel. Acta Med Scand $1983 ; 214: 361-5$.

7. Okamura K, Ueda K, Sone H, Ikenoue H, Hasuo Y, Sato K, et al. A sensitive thyroid stimulating hormone assay for screening of thyroid functional disorder in elderly Japanese. J Am Geriatr Soc 1989;37:317-22.

8. Parle JV, Franklyn JA, Cross KW, Jones SC, Sheppard MC. Prevalence and follow up of abnormal thyrotrophin (TSH) concentrations in the elderly in the United Kingdom. Clin Endocrinol 1991;34:77-83.

9. Runnels BL, Garry PJ, Hunt WC, Standefer JC. Thyroid function in a health elderly population: Implications for clinical evaluation. J Gerontol 1991;46(1):B39-B44.
10. Sundbeck $G$, Edén S, Jagenburg R, Lindstedt $G$. Thyroid disfunction in 85-year-old women. Influence of non-thyroidal illness and drug treatment. Acta Endocrinol (Copenh) 1991;125(5):475-86.

11. Bemben DA, Winn P, Hamm RM, Morgan L, Davis A, Barton E. Thyroid disease in the elderly. Part I. Prevalence of undiagnosed hypothyroidism. J Farm Pract 1994;38(6):577-82.

12. Bagehi N, Brown TR, Parish RF. Thyroid dysfunction in adults over age 55 years - A study in an urban U.S. community. Arch Intern Med 1990; 150:785-7.

13. Ronnov-Jessen $V$, Kirkegaard C. Hyperthyroidism - A disease of old age? Br Med J 1973; 1:41-5.

14. Sawin CT, Chopra D, Azizi F, Mannix JE, Bacharach P. The aging thyroid. Increased prevalence of elevated serum thyrotropin levels in the elderly. JAMA 1979;242:247-50.

15. Van Coevorden A, Laurent E, Decoster C, Kerkhofs $M$, Neve P, Van Cauter E, et al. Decreased basal and stimulated thyrotropin secretion in health elderly men. J Clin Endocr Metab 1989;69(1):177-85.

16. Sundbeck $G$, Jagenburg R, Johansson PM, Edén S, Lindstedt $G$. Clinical significance of low serum thyrotropin concentration by chemiluminometric assay in 85-yearold women and men. Arch Intern Med 1991;151:549-56.

17. Sawin CT, Geller A, Kaplan MM, Bacharach P, Wilson PWF, Hershman JM. Low thyrotropin in older persons without hyperthyroidism. Arch Intern Med 1991;151:165-8.

18. Hershman JM, Pekaky AE, Berg L, Solomon DH, Sawin CT. Serum thyrotropin and thyroid hormone levels in elderly and middle-aged euthyroid persons. J Am Geriatr Soc 1993:41:823-8.

19. Hesch RD, Gatz J, Jüppner H, Stubbe P. TBG-dependency of age related variations of thyroxine and triiodothyronine. Horm Metab Res 1977:9:141-6.

20. Livingston EH, Hershman JM, Sawin CT, Yoshikawa $\Pi$. Prevalence of thyroid disease and abnormal thyroid tests in older hospitalized and ambulatory persons. J Am Geriatr Soc 1987;35:109-14.

21. Larsen PR, Ingbar SH. The thyroid gland. Factors that influence thyroid hormone economy. In: Wilson JD, Foster DW. Williams' textbook of endocrinology. $8^{\text {th }}$ ed. Philadelphia: W.B. Saunders, 1992;376-84.

22. Szaboles I, Ploenes C, Bernard W, Herrman J. Screening of geriatric patients for thyroid dysfunction with thyrotropin-releasing-hormone test, sensitive thyrotropin and free thyroxine estimation. Horm Metab Res 1990;22:298-302.

23. Harman SM, Wehmann RE, Blackman MR. Pituitary-thyroid hormone economy in health aging men: Basal indices of thyroid function and thyrotropin responses to constant infusions of TRH. J Clin Endocrinol Metab 1984;58:320-6.

24. Kabadi UM, Rosman PM. Thyroid hormone indices in adult health subjects: No influence of aging. J Am Geriatr Soc 1988;36:312-6.

25. Rubenstein HA, Butler JR, Werner SC. Progressive decrease in serum triiodothyronine concentrations with human aging: Radioimmunoassay following extractions of serum. J Clin Endocrinol Metab 1973;37:247-53.

Arq Bras Endocrinol Metab vol 46 n 5 Outubro 2002 
26. Nishikawa M, Inada M, Naito K, Ishii H, Tanaka K, Mashio $Y$, et al. Age related changes of serum 3,3'-diiodothyronine, 3'5'-diiodothyronine, and 3,5-diiodothyronine concentrations in men. J Clin Endocrinol Metab 1980;52(3):517-22.

27. Hermann J, Rusche HJ, Kröll HJ, Hilger $P$, Krüskemper HL. Free triiodothyronine (T3) and thyroxine (T4) serum levels in old age. Horm Metab Res 1974;6:239-40.

28. Alderete VA. Disfunção tireóidea no idoso. In: Encontro Brasileiro de Tireóide, 6., 1995, Campinas. (S.I.: s.n.) (1995?)

29. Oliveira ILC. Disfunções tiroideanas em idosos - dados preliminares. In: Congresso Brasileiro de Endocrinologia e Metabologia, 220, 1996, Salvador. Arq Bras Endocrinol Metab: Resumo dos Trabalhos. 1996;171.

30. Canaris GJ, Manowitz NR, Mayor G, Ridgway EC. The Colorado thyroid disease prevalence study. Arch Intern Med 2000; 160(4):526-34.

31. Marcilio C. Dicionário de Pesquisa Clínica. Artes gráficas S.A., 1995; 140

32. Sawin CT, Castelli WP, Hershman JM, McNamara P, Bacharach $P$. The aging thyroid. Thyroid deficiency in the Framingham study. Arch Intern Med 1985; 145:13868.

33. Roti E, Gardini E, Minelli R, Bianconi L, Braverman LE. Prevalence of anti-thyroid peroxidase antibodies in serum in the elderly: Comparison with other tests for antithyroid antibodies. Clin Chem 1992;38(1):88-92.

34. Mariotti S, Franceschi C, Cossarizza A, Pinchera A. The aging thyroid. Endocr Rev 1995; 16(6):686-715.

35. Tunbridge WMG, Brewis M, French JM, Appleton D, Bird T, Clark F, et al. Natural history of autoimmune thyroiditis. Br Med J 1981;282:258-62.

36. Rosenthal MJ, Hunt WC, Garry PJ, Goodwin JS. Thyroidal failure in the elderly. Microssomal antibodies as discriminant for therapy. JAMA 1987;258:209-13.

37. Roti E, Gardini E, Minelli R, Bianconi L, Braverman LE. Prevalence of anti-thyroid peroxidase antibodies in serum in the elderly: Comparison with other tests for antithyroid antibodies. Clin Chem 1992;38(1):88-92.

38. Sawin CT, Bigos ST, Land S, Bacharach P. The aging thyroid. Relationship between elevated serum thyrotropin level and thyroid antibodies in elderly patients. Am J Med 1985; 79:591-5
39. Hawkins BR, Cheah PS, Dawkins RL, Whittingham S, Burger HG, Patel Y, et al. Diagnostic significance of thyroid microssomal antibodies in randomly selected population. Lancet 1980; Nov 15:1057-9.

40. Tomimori $E$, Pedrinola $F$, Cavaliere $H$, Knobel $M$, Medeiros-Neto $G$. Prevalence of incidental thyroid disease in a relatively low iodine intake area. Thyroid 1995;5(4):273-6.

41. Szaboles I, Ploenes C, Beyer M, Bernard W, Herrman J. Factors affecting the serum free thyroxine levels in hospitalized chronic geriatric patients. J Am Geriatr Soc 1993:41:742-6.

42. Kabadi UM, Premachandra BN. Low triiodothyronine and raised reverse triiodothyronine levels in patients over fifty years of age who have Type II Diabetes Mellitus: Influence of metabolic control, not age. J Am Geriatr Soc 1984;32(5):375-8.

43. Olsen T, Laurberg $P$, Weeke J. Low serum T3 and high serum reverse $\mathrm{T} 3$ in old age: An effect of disease, not age. J Clin Endocrinol Metab 1978;47:1111-5.

44. Bermudez F, Surks MI, Oppenheimer JH. High incidence of decreased serum triiodothyronine concentrations in patients with non thyroidal disease. J Clin Endocrinol Metab 1975;41(1):27-40.

45. Burrows AW, Shakespear RA, Hesch RD, Cooper E, Aickin $\mathrm{CM}$, Burke CW. Thyroid hormones in the elderly sick: T4 euthyroidism. Br Med J 1975;4:437-9.

46. Gregerman RI, Gaffney GW, Shock NW, Crowder SE. Thyroxine turnover in euthyroid man with special reference to changes with age. J Clin Invest 1962; 41(11):2065-73.

47. Jefferrys PM, Farran HEA, Hoffenberg R, Fraser PM, Hodkinson HM. Thyroid function tests in the elderly. Lancet 1972; Apr 29:924-7.

48. Ehrmann DA, Weinberg M, Sarne DH. Limitations to the use of a sensitive assay for TSH in the assessment of thyroid status. Arch Intern Med 1989;149:369-72.

\section{Endereço para correspondência:}

Suzan C. de Lacerda Mendonça Alameda Teodoro de Sá Filho 82 38411-198 Uberlândia, MG

e.mail: suzan_mendonga@starmedia.com 